OPEN ACCESS

Edited by:

Samuel Abiven,

University of Zurich, Switzerland

Reviewed by:

Thibault Lambert,

University of Liège, Belgium

Lori Ziolkowski,

University of South Carolina, USA

${ }^{*}$ Correspondence:

Thorsten Dittmar

thorsten.dittmar@uni-oldenburg.de

Specialty section:

This article was submitted to

Biogeoscience,

a section of the journal

Frontiers in Earth Science

Received: 27 June 2016

Accepted: 30 August 2016

Published: 22 September 2016

Citation:

Riedel T, Zark M, Vähätalo AV, Niggemann J, Spencer RGM,

Hernes PJ and Dittmar T (2016)

Molecular Signatures of Biogeochemical Transformations in Dissolved Organic Matter from Ten World Rivers. Front. Earth Sci. 4:85.

doi: 10.3389/feart.2016.00085

\section{Molecular Signatures of Biogeochemical Transformations in Dissolved Organic Matter from Ten World Rivers}

\author{
Thomas Riedel ${ }^{1}$, Maren Zark ${ }^{1}$, Anssi V. Vähätalo ${ }^{2}$, Jutta Niggemann ${ }^{1}$, \\ Robert G. M. Spencer ${ }^{3}$, Peter J. Hernes ${ }^{4}$ and Thorsten Dittmar ${ }^{1 *}$ \\ ${ }^{1}$ Research Group for Marine Geochemistry (ICBM-MPI Bridging Group), Institute for Chemistry and Biology of the Marine \\ Environment (ICBM), Carl von Ossietzky University, Oldenburg, Germany, ${ }^{2}$ Department of Biological and Environmental \\ Science, University of Jyväskylä, Jyväskylä, Finland, ${ }^{3}$ Department of Earth, Ocean and Atmospheric Science, Florida State \\ University, Tallahassee, FL, USA, ${ }^{4}$ Department of Land, Air and Water Resources-Hydrology, University of California, Davis, \\ Davis, CA, USA
}

Rivers carry large amounts of dissolved organic matter (DOM) to the oceans thereby connecting terrestrial and marine element cycles. Photo-degradation in conjunction with microbial turnover is considered a major pathway by which terrigenous DOM is decomposed. To reveal globally relevant patterns behind this process, we performed photo-degradation experiments and year-long bio-assays on DOM from ten of the largest world rivers that collectively account for more than one-third of the fresh water discharge to the global ocean. We furthermore tested the hypothesis that the terrigenous component in deep-sea DOM may be far higher than biomarker studies suggest, because of the selective photochemical destruction of characteristic biomolecules from vascular plants. DOM was molecularly characterized by a combination of non-targeted ultrahigh-resolution mass spectrometry and quantitative molecular tracer analyses. We show that the reactivity of DOM is globally related to broad catchment properties. Basins that are dominated by forest and grassland export more photo-degradable DOM than other rivers. Chromophoric compounds are mainly vascular plant-derived polyphenols, and partially carry a pyrogenic signature from vegetation fires. These forest and grassland dominated rivers lost up to $50 \%$ of dissolved organic carbon (DOC) during irradiation, and up to $85 \%$ of DOC was lost in total if subsequently bio-incubated for 1 year. Basins covered by cropland, on the other hand, export DOM with a higher proportion of photo-resistant and bio-available DOM which is enriched in nitrogen. In these rivers, $30 \%$ or less of DOC was photodegraded. Consistent with previous studies, we found that riverine DOM resembled marine DOM in its broad molecular composition after extensive degradation, mainly due to almost complete removal of aromatics. More detailed molecular fingerprinting analysis (based on the relative abundance of $>4000$ DOM molecular formulas), however, revealed clear differences between degraded riverine and deep-sea DOM (molecular Bray-Curtis dissimilarity of 50\%). None of our experimental treatments enhanced the molecular similarity between the rivers and the 
deep ocean. We conclude that terrigenous DOM retains a specific molecular signature during photo-degradation on much longer time scales than previously assumed and that substantial, thus far unknown, molecular transformations occur prior to downward convection into the deep oceanic basins.

Keywords: dissolved organic matter, world rivers, photo-degradation, bio-degradation, ultra-high resolution mass spectrometry, lignin, black carbon

\section{INTRODUCTION}

Rivers and streams transport large amounts of carbon to the oceans thereby connecting the terrestrial with the marine carbon cycle (Aufdenkampe et al., 2011; Raymond and Spencer, 2015). About $0.25 \mathrm{Pg}$ of dissolved organic carbon (DOC) is carried annually via the riverine pathway into the global coastal ocean (Hedges et al., 1997; Dai et al., 2012). During transport of riverine dissolved organic matter (DOM), biotic and abiotic processes alter DOM concentration and composition (Cole et al., 2007). Mineralization turns large parts of DOM into dissolved inorganic carbon, part of which is evaded to the atmosphere as $\mathrm{CO}_{2}$ (Lapierre et al., 2013; Raymond et al., 2013; Koehler et al., 2014).

Once released from soils into aqueous environments, a portion of DOM is quickly turned over by microorganisms (Ward et al., 2013), but some compounds resist immediate decomposition and are not degraded in year-long incubation experiments (Vähätalo and Wetzel, 2008). Many of the terrigenous compounds that escape fast microbial degradation are aromatic in nature. For instance, pyrogenic polycyclic aromatics are among the most resistant forms of organic matter in soils and aqueous environments (Santín et al., 2016). Most aromatic compounds absorb ultraviolet (UV) radiation and are thus susceptible to photo-degradation. Therefore, photodegradation plays a major role in the fate of terrigenous DOM in sunlit surface waters (Osburn et al., 2009; Stubbins et al., 2010; Cory et al., 2014), and affects the quantity and composition of DOM. The oxidation of DOM yields inorganic carbon and nutrients such as ammonium (Miller and Zepp, 1995; Miller and Moran, 1997; Graneli et al., 1998; Vähätalo et al., 2003; Lapierre et al., 2013). Besides the direct terminal oxidation, the formation of low molecular weight compounds such as pyruvate, maleic or fumaric acid has also been observed (Mopper et al., 1991; Gerdes et al., 1997). As a result, the transformation of DOM into more bio-available substrates stimulates microbial growth thereby enhancing the effect of abiotic photo-chemical oxidation of DOM (Mopper et al., 1991; Lindell et al., 1995; Miller and Moran, 1997; Vähätalo and Wetzel, 2008; Aarnos et al., 2012). Exposure to UV radiation may also decrease microbial activity (Tranvik and Bertilsson, 2001), possibly due to radiation-induced damage to the organisms (Karentz et al., 1994), transformation of bio-labile DOM into recalcitrant forms (Obernosterer et al., 1999), photo-mineralization of bio-available DOM (Obernosterer and Benner, 2004) or the production of inhibitory substances (Lund and Hongve, 1994).

Exposure to sunlight and subsequent microbial decomposition particularly affect those compounds that are typical for a terrestrial origin, mainly polyphenols. Therefore, after extensive photo- and microbial degradation, terrigenous DOM resembles marine DOM in its molecular composition (Dittmar et al., 2007; Stubbins et al., 2010; Rossel et al., 2013). The combined effect of photo- and microbial degradation seems to result in the accumulation of refractory molecules that share very similar molecular structures, independent of their original source (Jaffé et al., 2012). A universal, source-independent molecular character of the residuals of organic matter degradation in aquatic systems would have major implications. Degradation pathways, rather than the original source would determine the long-term fate of DOM in the ocean, and source assignment via molecular tracers would become more and more difficult in the progression of organic matter degradation.

Here, we address this topic by studying the impact of intense photo-degradation and year-long biodegradation on the molecular composition of DOM from ten of the largest world rivers. The results provide an overall pattern of DOM composition on a global scale that can be used to infer degradability and transformation of freshwater DOM and ultimately define the fate of riverine DOM in the sunlit hydrosphere. The studied rivers account for about one third of the global freshwater discharge to the oceans, and integrate characteristics of DOM from the watersheds covering 25\% of global land area in five continents across contrasting biomes and latitudes. The DOM molecular composition of these large rivers varies systematically with land use (Wagner et al., 2015). In particular, the proportion of cropland has a major influence on the presence of nitrogen and sulfur in riverine DOM (Wagner et al., 2015). Here, we examined the same samples as in Wagner et al. (2015). Each river was sampled once during the season of peak discharge. Due to logistical reasons, the samples had to be transported to the laboratory unfiltered and at environmental temperature and had to be stored after filtration at $4^{\circ} \mathrm{C}$ for different time spans before they were further processed. The samples thus represent a snapshot in time, and at least a fraction of the most bio-labile DOM had been degraded prior to further experiments and analyses. Despite these inherent limitations, systematic variations of the molecular DOM composition as a function of land cover and land use had been preserved (Wagner et al., 2015).

In order to disentangle the molecular imprints of microbial and photo-degradation, sequential experiments were conducted with the 10 river samples. First, samples were irradiated with artificial sunlight to remove essentially all light-absorbing (chromophoric) DOM, and afterwards, the photo-irradiated samples were incubated for 1 year with natural riverine microbial communities. All experiments were accompanied with dark controls. In natural sunlit waters, microbial and photo-chemical 
processes occur simultaneously, and the succession of microbial communities differs in nature compared to long-term laboratory incubations (Petersen and Kemp, 2010). The goal of this study was not the full reproduction of these natural processes, but instead reductionist experiments that aimed in resolving the following research questions:

(1) Is the reactivity of riverine DOM, in terms of photoand bio-degradability under defined laboratory conditions, related to land-cover and land use?

(2) Do the molecular modifications induced by photo- and bio-degradation follow predictable patterns across the rivers?

(3) Is there a universal molecular signature of resistant DOM across the major world rivers and the deep ocean?

To approach these questions we combined a non-targeted ultrahigh-resolution mass spectrometric approach with conventional quantitative molecular tracer analyses. Specifically, ultrahigh-resolution Fourier-transform ion cyclotron resonance mass spectrometry (FT-ICR-MS) resolved thousands of molecular formulas in DOM and, in conjunction with relative signal intensities for each of these formulas, most detailed molecular fingerprints were obtained for each sample. Ligninderived phenols were quantified as a natural biomarker for vascular-plant derived DOM and benzenepolycarboxylic acids as tracer for pyrogenic DOM, i.e., dissolved black carbon (DBC).

\section{MATERIALS AND METHODS}

\section{River Water Sampling}

Ten major world rivers (for details see Lalonde et al., 2014) were sampled during the season of highest discharge. Water samples were taken by local operators at each river (see acknowledgments) following a standardized protocol by immersing pre-cleaned polyethylene containers (consecutively cleaned with detergent, acid, and ultrapure water). The sample named "Amazon" is a composite sample prepared from water of Rio Negro (25\%) and Rio Solimoes (75\%). All samples were kept in the dark and not filtered or poisoned prior to shipping. The containers were express-shipped to the laboratory in Helsinki. After arrival, the samples were filtered $(1 \mu \mathrm{m}$ Nucleopore QR 10IN or Graver Technologies VTEC 1-10PS) and stored at $4^{\circ} \mathrm{C}$ between 7 (Amazon) and 341 days (Yangtze). During transport and storage, microbial activity removed at least a fraction of biolabile DOM prior to the start of the experiments. In the case of the St. Lawrence River this accounted for $19 \%$ of DOC (Lalonde et al., 2014). Additional information regarding sampling and sample preparation can be found in accompanying publications (Jaffé et al., 2013; Lalonde et al., 2014; Wagner et al., 2015).

\section{Photo-Degradation and Bioassay}

The experiment consisted of two phases as described in Lalonde et al. (2014): a photochemistry-phase followed by a bioassayphase consisting of a 1-year long microbial incubation in the dark. Briefly, the irradiation experiment was designed to remove all chromophoric DOM through abiotic photochemical reactions. Direct photochemical reactions of DOM are possible only when DOM contains chromophores (i.e., chromophoric dissolved organic matter, CDOM) that can absorb solar radiation at wavelengths $>300 \mathrm{~nm}$. The experimental conditions in the solar-simulator were chosen to remove $>96 \%$ of CDOM (absorbance at $350 \mathrm{~nm}$ ). Before the start of the radiation experiments samples were filtered through $0.2 \mu \mathrm{m}$ filters (Cellulose Acetate, Sartorius). Samples were placed in acidwashed $\left(\mathrm{HNO}_{3}\right.$, following copious rinsing with ion-exchanged Milli-Q water) and combusted $\left(>2 \mathrm{~h}, 450^{\circ} \mathrm{C}\right) \mathrm{UV}$-transparent $750 \mathrm{~mL}$ quartz vials fitted with ground glass stoppers. A headspace corresponding to $10 \%$ of the vial internal volume was filled with oxygen gas, which was replenished after 4 days of irradiation to ensure complete oxidation of the UV-sensitive DOM fraction (Vähätalo and Wetzel, 2008). The samples were submerged $(\sim 1 \mathrm{~cm})$ in a flow-through pool of tap water regulated to $25^{\circ} \mathrm{C}$ and irradiated for 10 days with metal halide lamps (Thorn OQ 1000) and fluorescent tubes (UVA-340, Q-Lab Corp.). The lamps simulated well the photo-chemically active part of natural solar radiation (Figure S1). The irradiance incident to the samples integrated from 280 to $350 \mathrm{~nm}$ was $28.9 \mathrm{~W} \mathrm{~m}^{-2}$ and 16.4 times higher than the corresponding global mean natural solar radiation at the sea surface. The ultraviolet radiation dose received by the samples over the 10-day experiment corresponded to an average of half-a-year dose of the natural solar radiation mentioned above (Lalonde et al., 2014). The high UV-irradiance kept the water samples sterile during the 10 days of irradiation. The sterility was additionally confirmed by the absence of bacterial cells in the samples prepared for epifluorescence microscopy (Aarnos et al., 2012). A second set of samples was treated as dark controls similar to the irradiated samples, but was kept in glass bottles wrapped in aluminum foil at room temperature.

After 10 days, irradiated samples as well as dark controls were sampled for analysis and subsequently received unfiltered water from each river as a microbial inoculum $(10 \mathrm{~mL}$ inoculum to $1000 \mathrm{~mL}$ of treated sample) along with the addition of $\mathrm{KH}_{2} \mathrm{PO}_{4}$ to adjust the molar $\mathrm{N}$ to $\mathrm{P}$ ratio in the samples to approx. nine which is the typical ratio of bacterioplankton biomass (Goldman et al., 1987). Thus, phosphorus limitation of the microbial communities was eliminated. Samples were incubated at $22^{\circ} \mathrm{C}$ in the dark for 1 year.

We use the following abbreviations for the various experiments:

"initial": untreated initial water (as in Wagner et al., 2015).

"D": 10 days of dark incubation of sample "initial" without addition of inoculum and phosphate (dark control of the photo-degradation experiments).

"D+": 1 year of dark incubation of sample " $D$ " with addition of inoculum and phosphate.

"L": 10 days of photo-degradation of sample "initial."

"L+": 1 year of dark incubation of sample "L" with addition of inoculum and phosphate.

\section{DOC and CDOM Analysis}

After the experiments, the irradiated and the dark control waters were sampled for the determination of DOC, CDOM, dissolved lignin, dissolved black carbon (DBC), and for molecular 
characterization of DOM via FT-ICR-MS. The absorbance of CDOM was measured against ultrapure water and converted into absorption coefficients (Aarnos et al., 2012). The concentrations of DOC were measured as non-purgeable organic carbon in $0.2 \mu \mathrm{m}$ filtered waters acidified to $\mathrm{pH} 2$ (with $\mathrm{HCl} 32 \%$, ultrapure) via high temperature catalytic oxidation using a Shimadzu TOCV CPH carbon analyzer. Replicate analyses of a deep sea reference material (DSR, provided by D. Hansell, University of Miami, USA) yielded an accuracy and precision of $<5.2 \%$. Solid-phase extracted DOC (SPE-DOC, see below) was determined in the same way, after the methanol extracts were dried by evaporation and re-dissolved in ultra-pure water.

\section{Sample Preparation for Molecular Analysis}

All samples were solid phase extracted (SPE) prior to molecular analysis. SPE was performed according to Dittmar et al. (2008) using Varian Bond Elute PPL cartridges (100 mg) as solid phase. This is one of the most efficient methods available to date for the complete desalting of natural DOM samples, as it removes salt to undetectable traces and $>50 \%$ of DOC is routinely recovered (Green et al., 2014). Cartridges were rinsed with $2 \mathrm{~mL} \mathrm{MeOH}$ (analytical grade) prior to use. Samples were acidified to $\mathrm{pH} 2$ with $\mathrm{HCl}$ (32\%, ultrapure) and allowed to pass through the cartridges under gravity. Cartridges were rinsed two times with $0.01 \mathrm{M} \mathrm{HCl}$ for removal of salt, dried with a stream of argon and immediately extracted with $1 \mathrm{~mL}$ of $\mathrm{MeOH}$ (analytical grade). Extraction efficiencies were determined on evaporated extracts, re-dissolved in ultrapure water, and were $56 \pm 12 \%$ for initial and dark control samples and $35 \pm 12 \%$ for irradiated samples on a carbon basis (this is further discussed below).

\section{Black Carbon and Lignin Molecular Analysis}

DBC was determined via benzenepolycarboxylic acids (BPCAs) released by hot nitric acid oxidation of SPE-DOM, according to Dittmar (2008) with the modification as described in Stubbins et al. (2015). Briefly, aliquots of the SPE-DOM samples were transferred into pre-combusted $\left(400^{\circ} \mathrm{C}, 4 \mathrm{~h}\right)$ glass ampoules. The methanol was evaporated in a centrifugal vacuum evaporator (Christ RV2-18) and the samples re-dissolved in $0.5 \mathrm{~mL}$ nitric acid (65\%, analytical grade). The ampoules were fire sealed and heated in a stainless steel pressure bomb at $170^{\circ} \mathrm{C}$ for $9 \mathrm{~h}$. Afterwards, the nitric acid was evaporated in a centrifugal vacuum evaporator (Christ RV2-18) and the samples redissolved in the mobile phase of the liquid chromatography. BPCAs were then determined via ultra-performance liquid chromatography (Waters Acquity UPLC). Concentrations of BPCAs were converted into concentrations of DBC, according to Dittmar (2008), with the slight modification described in Stubbins et al. (2015). The analytical error (variability between replicate analysis) was $<10 \%$.

Lignin phenols were determined via the $\mathrm{CuO}$ oxidation method described by Hedges and Ertel (1982), with modifications as outlined by Spencer et al. (2010). In brief, SPE-DOM was transferred to Monel reaction vessels (Prime Focus) and dried under vacuum centrifugation. All samples were alkaline oxidized at $155^{\circ} \mathrm{C}$ in a stoichiometric excess of $\mathrm{CuO}$, followed by acidification to $\mathrm{pH} 1\left(6 \mathrm{M} \mathrm{H}_{2} \mathrm{SO}_{4}\right.$, analytical grade) and extracted three times with ethyl acetate (analytical grade), passed through $\mathrm{Na}_{2} \mathrm{SO}_{4}$ (analytical grade) drying columns and taken to dryness under a gentle stream of ultrapure nitrogen. After redissolution in pyridine (analytical grade), lignin phenols were silylated (with BSTFA, analytical grade), and quantified on a gas chromatography mass spectrometry system (Agilent 6890 gas chromatograph equipped with an Agilent 5973 mass selective detector and a DB5-MS capillary column; $30 \mathrm{~m}, 0.25 \mathrm{~mm}$ inner diameter, Agilent) using cinnamic acid as an internal standard and a five-point calibration scheme. Six lignin phenols were quantified for all samples, including three vanillyl phenols (vanillin, acetovanillone, vanillic acid), and three syringyl phenols (syringaldehyde, acetosyringone, syringic acid) (Spencer et al., 2010). The analytical error (variability between replicate analysis) was $<10 \%$. Lignin concentrations in river water are expressed as the sum of all detected phenols. The expression $\lambda$-lignin $(\%)$ is the sum of all lignin phenols $\left(\mu \mathrm{g} \mathrm{L}^{-1}\right)$ divided by the concentration of DOC $\left(\mathrm{mg} \mathrm{L}^{-1}\right)$.

\section{FT-ICR-MS Analysis}

FT-ICR-MS analyses were conducted on solid-phase extracted samples diluted with ultrapure water to $1: 1 \mathrm{MeOH} /$ water (v/v) to a DOC concentration of $20 \mathrm{mg} \mathrm{L}^{-1}$. Samples were ionized in negative ionization mode using electrospray ionization (ESI) and analyzed on a Bruker Solarix 15 Tesla FT-ICR-MS at the University of Oldenburg (Germany).

The lower mass limit was set to $m / z$ 150. 500 scans were accumulated per sample. Spectra were internally calibrated using an in-house reference mass list. After internal calibration the mass error was less than $100 \mathrm{ppb}$ over the entire mass range. Molecular formulas considering the elements $\mathrm{C}, \mathrm{H}, \mathrm{O}, \mathrm{N}, \mathrm{S}$, and $\mathrm{P}$ were assigned based on rules published in Koch et al. (2007). We used a method detection limit (MDL) based on the uncertainty of the noise derived from repeated analysis of blank samples (Riedel and Dittmar, 2014). This approach is superior to the commonly used fixed signal-to-noise ratio, as it filters noise peaks much more reliably from FT-ICR mass spectra (Riedel and Dittmar, 2014). All molecular formulas were detected as singly-charged negative ions.

The molecular formula of a molecule provides a wealth of information such as hetero-atom content, degree of oxidation, or saturation. With help of the aromaticity index $\left[\mathrm{AI}_{\text {mod }}\right.$, Koch and Dittmar (2006), as corrected and reported in the erratum (Koch and Dittmar, 2016)] and element ratios, formulas can be grouped into compound classes (Šantl-Temkiv et al., 2013; Riedel et al., 2014; Seidel et al., 2014). It is important to note that multiple structural isomers can exist for each molecular formula, but the following categories provide a helpful overview of likely structure behind a given molecular formula. They should not be interpreted as unambiguous structural assignments. Five categories were defined here and the molecular formulas in each sample were grouped into one of these categories. "Aliphatics" were defined as molecules with $\mathrm{H} / \mathrm{C}$ ratios $\geq 1.5$. "Highly unsaturated compounds" that include also phenols with aliphatic side-chains, as well as carboxyl-rich alicyclic molecules (CRAM, Hertkorn et al., 2006) were defined as $\mathrm{H} / \mathrm{C}<1.5$ and 
$\mathrm{AI}_{\text {mod }} \leq 0.5$. This group was further sub-divided into oxygen rich $(\mathrm{O} / \mathrm{C}>0.5)$ and oxygen poor $(\mathrm{O} / \mathrm{C} \leq 0.5)$ compounds. "Polyphenols" contain polyphenolic as well as polycondensed aromatic compounds with aliphatic side-chains and were defined by $0.5<\mathrm{AI}_{\text {mod }} \leq 0.66$ (Koch and Dittmar, 2006). Accordingly, "polycondensed aromatics" were defined by $\mathrm{AI}_{\text {mod }}>0.66$. Unsaturated, polyphenolic and condensed aromatic compounds, albeit also present in marine DOM (Hertkorn et al., 2006), are particularly abundant in terrestrial systems, because vascular plants are the main producers of phenolic compounds on the planet.

\section{Statistical Analysis}

For all statistical analyses, the same number $(n=1456)$ of molecular formulas was considered for each river sample, resulting in a total number of 4048 different molecular formulas across all samples. For this selection, the 1456 molecular formulas with the highest FT-ICR-MS signal intensity were chosen for each sample; 1456 was the lowest number of molecular formulas detected in a single sample. The data were then normalized to the sum of signal intensities of the respective sample and finally used for statistical analysis. This data treatment ensured most robust statistical analysis, because the number of detected compounds is strongly influenced by minor analytical shifts or differences in SPE-DOC concentration since many compounds are detected at signal intensities close to the detection limit (Riedel and Dittmar, 2014). By considering the same number of the most intense signals in each sample, such analytical artifacts are avoided. Furthermore, statistical robustness is enhanced by using the same number of variables for each sample. Analytical reproducibility was assessed by analyzing a marine reference sample (see below) eight times. This sample was included in all statistical analyses.

To relate bulk properties of the initial samples (e.g., bio- and photo-degradability) to the relative abundance of molecular formulas $(n=2167$ molecular formulas in the initial river water sample set), linear correlation analyses (Pearson) were performed. In addition, a principle component analysis (PCA) was carried out to highlight the dominant patterns and trends in the FT-ICR-MS data. The PCA was calculated based on the relative signal intensities of the molecular formulas $(n=4048$ different molecular formulas in the entire sample set). Furthermore, the molecular similarity of SPEDOM between samples (with respect to the relative signal intensities of the molecular formulas) was assessed via a Bray Curtis dissimilarity analysis (Osterholz et al., 2015). As an alternative to these statistical analyses that considered the FT-ICR-MS signal intensities of each molecular formula, a simple presence / absence analysis was performed. A molecular formula was considered "present" if its signal intensity was above the MDL. Based on the presence and absence in the respective samples, molecular formulas were categorized as photo-stable, photo-labile, photo-produced and other categories (Table S2). Results are displayed in frequency plots (Figure 6 and Figure S6).

We added a sample from the North Equatorial Pacific Intermediate Water (NEqPIW, sampled at station NELHA off Big Island in Hawaii at $674 \mathrm{~m}$ water depth) in our comparison, which is considered to be one of the oldest water masses on Earth (Stuiver et al., 1983; Osterholz et al., 2015) that was extracted and measured by the same methods used in this study (Green et al., 2014). The sample was analyzed eight times, during the

TABLE 1 | The effects of simulated sunlight and microbial degradation on the concentration of riverine DOC.

\begin{tabular}{|c|c|c|c|c|c|c|c|c|c|c|c|}
\hline & & Amazon & Congo & Danube & Ganges Brahma. & Lena & Mekong & Mississippi & Paraná & St. Lawrence & Yangtze \\
\hline $\mathrm{DOC}\left(\mathrm{mg} \mathrm{L}^{-1}\right)$ & initial & 4.4 & 6.7 & 2.4 & 0.8 & 5.8 & 1.6 & 3.4 & 2.5 & 3.8 & 1.7 \\
\hline \multirow[t]{3}{*}{$\Delta \mathrm{DOC}$ (\% of initial) } & $\mathrm{D}+$ & -25 & -15 & -25 & -25 & -16 & -25 & -12 & -24 & -18 & -24 \\
\hline & $\mathrm{L}$ & -36 & -49 & -33 & -13 & -28 & -19 & -24 & -24 & -18 & -29 \\
\hline & $\mathrm{L}+$ & -80 & -85 & n. a. & -38 & -62 & -56 & -68 & -64 & -63 & -71 \\
\hline $\operatorname{CDOM}\left(m^{-1}\right)$ & initial & 13 & 26 & 3.0 & 0.89 & 9.1 & 2.3 & 4.8 & 3.6 & 5.3 & 2.0 \\
\hline$\Delta \mathrm{CDOM}(\%$ of initial) & $\mathrm{L}$ & -99 & -100 & -97 & -96 & -97 & -99 & -98 & -97 & -98 & -97 \\
\hline $\mathrm{DBC}\left(\mu \mathrm{g} \mathrm{L}^{-1}\right)$ & initial & 293 & 562 & 152 & 36 & 353 & 85 & 235 & 205 & 255 & 88 \\
\hline \multirow[t]{3}{*}{$\Delta \mathrm{DBC}(\%$ of initial) } & $\mathrm{D}+$ & -20 & -10 & -39 & -17 & -20 & -18 & -17 & -1 & -35 & -43 \\
\hline & $\mathrm{L}$ & -82 & -93 & -87 & -53 & -57 & -88 & -83 & -68 & -75 & -84 \\
\hline & $\mathrm{L}+$ & -95 & -96 & n. a. & -83 & -81 & -84 & -94 & -90 & -94 & -92 \\
\hline \multirow[t]{2}{*}{ CDOM/DOC $\left(\mathrm{m}^{2} \mathrm{~g}^{-1}\right)$} & initial & 3.1 & 3.9 & 1.2 & 1.1 & 1.6 & 1.4 & 1.4 & 1.5 & 1.4 & 1.2 \\
\hline & $\mathrm{L}$ & 0.05 & 0.04 & 0.05 & 0.06 & 0.07 & 0.05 & 0.04 & 0.06 & 0.04 & 0.05 \\
\hline \multirow[t]{4}{*}{ DBC/DOC (\% carbon) } & initial & 6.7 & 8.4 & 6.3 & 4.5 & 6.1 & 5.3 & 6.9 & 8.2 & 6.7 & 5.2 \\
\hline & $\mathrm{D}+$ & 7.1 & 8.8 & 5.1 & 5.0 & 5.8 & 5.8 & 6.5 & 10.6 & 5.4 & 3.8 \\
\hline & $\mathrm{L}$ & 1.9 & 1.2 & 1.3 & 2.4 & 3.6 & 0.8 & 1.5 & 3.5 & 2.1 & 1.2 \\
\hline & $\mathrm{L}+$ & 1.7 & 2.0 & n. a. & 1.2 & 3.0 & 2.0 & 1.3 & 2.2 & 1.1 & 1.4 \\
\hline
\end{tabular}

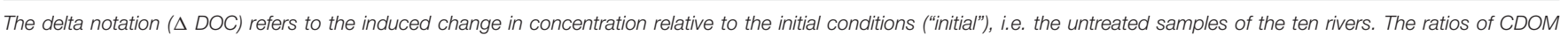

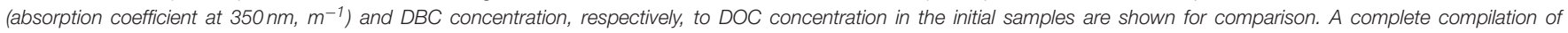
concentration data is in Table S1. For abbreviations, see material and methods, n.a.: data not available. 
same period as the river samples. The eight replicate analyses of NEqPIW were used to assess analytical variability in all statistical analyses.

All statistics were performed using the software package $\mathrm{R}$ (Version 3.2.3, package "vegan" Oksanen et al., 2013).

\section{RESULTS AND DISCUSSION}

\section{Is the Reactivity of Riverine DOM Related to Land Cover?}

During the year-long dark microbial incubation of the untreated river samples ("D+"), $21 \%$ of DOC was lost on average $( \pm 5 \%$ standard deviation, Table 1). This is comparable to the loss during the 10 days of intense photo-irradiation ("L") where on average $27 \%( \pm 11 \%)$ of DOC was removed. The microbial incubation of the photo-degraded sample ("L+") was similarly efficient in DOC removal, and in sum $64 \%( \pm 15 \%)$ of DOC was lost by sequential photo- and bio-degradation. This is consistent with photochemical transformation of DOC to $\mathrm{CO}_{2}$ and biologically labile photoproducts, which are effectively assimilated by microbes (Miller and Zepp, 1995; Graneli et al., 1998; Vähätalo and Wetzel, 2008; Cory et al., 2014). The dark control of the photo-degradation experiment ("D") did not significantly change in DOC concentration which is not surprising, given that it was filtered $(0.2 \mu \mathrm{m})$ prior to incubation and much of the bio-labile DOM had presumably been removed prior to the experiment.

Pronounced differences in DOM reactivity were observed between the individual rivers (Table 1 and Table S1). For instance, almost half of DOC was removed by photo-degradation from the Congo River, while only $13 \%$ of DOC was susceptible to photo-degradation in the Ganges-Brahmaputra River. Also bio-degradation varied strongly between rivers. Neither photo-, nor bio-degradability of any of the analyzed parameters was related to storage time of the samples prior to the experiment (student's $t$-test of $\Delta$-values vs. storage time; $r^{2}<0.1 ; p>0.1$; $n=10$ ). Thus, differences in sample handling and processing were not the prime reason for the observed differences. Some watershed characteristics (data from Wagner et al., 2015), however, appeared to influence DOM reactivity (Figure 1). DOM from large basin areas with a high proportion of forests or grasslands was most susceptible to photo-degradation. For instance, in the Congo (90\% of forest and grassland) almost $50 \%$ of DOC was removed by sterile irradiation (L), while in the Ganges-Brahmaputra (35\% of forest and grassland) only about $10 \%$. Agricultural use (large proportion of cropland) diminished photo-degradability, but was positively related to bio-degradability. For instance, in the Danube (almost 70\% cropland) about $25 \%$ of DOC was biodegraded (D+), similar to Yangtze (almost $50 \%$ of cropland), while in the Congo or Lena $(<10 \%$ cropland), only about $15 \%$ was removed. This observed trend is consistent with the finding that CDOM decreases with enhanced farming, while the amount of chromophores increases with wetland cover (Wilson and Xenopoulos, 2009). Compositional differences of DOM in rivers and lakes as a function of catchment properties have also been demonstrated by others (Mattsson et al., 2009; Jaffé et al., 2012; Lambert

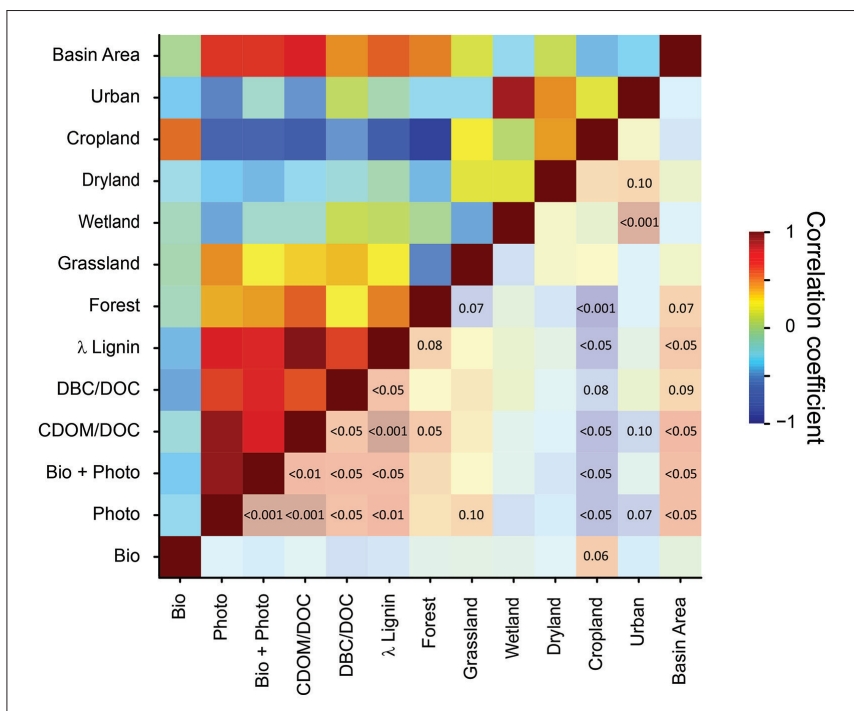

FIGURE 1 | Correlation matrix of catchment properties of the ten studied world rivers, molecular and optical properties of the untreated ("initial") river samples, and the corresponding values of bio- and photo-reactivity of each samples ( $\Delta$ DOC, \% of initial, Table 1). Data for land cover are from Wagner et al. (2015). Linear Pearson correlation was performed $(n=10)$. The color code represents the corresponding correlation coefficients $(r)$. In the lower right triangle of the matrix, $p$-values are superimposed onto the same (but lighter) color scheme $(p>0.1$ are omitted).

et al., 2015; Wagner et al., 2015), and related to DOM reactivity (Remington et al., 2011). Our study now shows that the influence of land cover on DOM reactivity follows a globally consistent trend, across a wide range of world rivers. The studied rivers are from high-latitude to tropical rivers, and differ in catchment morphology. Despite these obvious differences, the influence of land cover on DOM composition and reactivity appears universal.

The CDOM/DOC ratio of the initial river samples was highly significantly correlated with photo-degradability of DOC $(p<$ $0.001, n=10$; Figure 1), providing a good predictor for photo-degradability of DOM. Degradability is defined here as the loss of DOC due to the experimental treatment $(\triangle \mathrm{DOC}$ in Table 1). CDOM is defined as the absorption coefficient at a wavelength of $350 \mathrm{~nm}$ (see methods). As a rule of thumb, a reduction of the CDOM/DOC ratio by 1 unit $\left(\mathrm{m}^{2} \mathrm{~g}^{-1}\right)$, resulted in $10 \%$ less DOC removal due to irradiation (slope of linear regression in Figure 1, see also data in Table 1). A highly significant correlation between $\lambda$-lignin and CDOM/DOC ( $p<0.001, n=10$; Figure 1) suggests that the main source of photodegradable CDOM in the forested and grassy basins is derived from vascular plant debris. The correlation with DBC/DOC indicates that DOM with high CDOM/DOC has also an elevated proportion of pyrogenic DOM. Bio-degradability, on the other hand, was inversely correlated with lignin, indicating that in the basins covered by cropland soft plant tissue with low content of lignin or non-vascular organisms are the main sources of bio-degradable DOM. Consistent with previous observations (Hernes and Benner, 2003; Benner and Kaiser, 2011; Fichot and Benner, 2012; Stubbins et al., 2015), the concentrations of 
aromatic compounds (lignin and DBC) correlated with CDOM (Figure S2).

On a broader molecular level, thousands of molecular formulas detected in the initial river samples significantly correlated with bio- or photo-degradability of DOM (Figure 2). The molecular-level trends are consistent with that observed for CDOM, DBC and lignin. Overall, highly unsaturated compounds positively correlated with the photo-degradability of a given sample, while more saturated compounds inversely correlated with photo-degradability (Figure 2B). This is consistent with the molecular trends observed in other photo-degradation experiments (Opsahl and Benner, 1998; Gonsior et al., 2008; Spencer et al., 2009; Seidel et al., 2015). Bio-degradability, on the other hand, was related to degree of oxygenation $(\mathrm{O} / \mathrm{C})$ and nitrogen content (Figure 2A). The compounds with low oxygen numbers were more easily bio-degraded than others. At first view, this finding is in direct contradiction to short-term bio-incubation studies of DOM from the Amazon River and other streams (Kim et al., 2006; Seidel et al., 2015; Medeiros et al., 2015). In all these experiments, oxygen-rich molecules were preferentially degraded in the course of a few days, while compounds with low oxygen content were preferentially produced. One has to keep in mind, however, that these early stages of degradation occurred already prior to our experiment. In our study, the abundance of low-oxygen compounds in the bio-degradable samples may be an indication for bacterially produced biomass, which in turn is likely more bio-labile than vascular plant debris. Consistent with this explanation is the finding that many of the compounds that correlated positively with the bio-degradability of DOM contained nitrogen (Figure 2A), most of which fall in our category of "peptides." For the same samples examined in this study, Wagner et al. (2015) pointed out that the use of nitrogen fertilizers in agricultural fields can lead to elevated content of nitrogen in DOM draining croplands.

In conclusion, bio- and photo-degradability of riverine DOM can globally be related to broad catchment properties. Independent of latitude, basins that are dominated by forest and grassland export photo-degradable DOM with a large proportion of chromophoric, phenolic compounds. Basins covered by cropland, on the other hand, export DOM with a relatively lower contribution of chromophores, but with more bio-available DOM which is enriched in nitrogen and likely of microbial origin. Thus, on a broad global scale land-use appears to be one of the main drivers for the reactivity and molecular composition of riverine DOM.

\section{Molecular Modifications Induced by Photo- and Bio-Degradation}

So far, we have discussed relationships between land cover, bulk DOM reactivity and molecular DOM composition in the rivers. In the following we relate these statistical relationships to the actual molecular changes induced by bio- and photo-degradation in our experiments.

The majority of molecular formulas did not disappear, but the photo-degradation experiment induced broad shifts in their abundance distribution (Figures 3, 4). Consistent with the almost complete removal of chromophores (CDOM) and previous experiments (Gonsior et al., 2008; Stubbins et al., 2010; Seidel et al., 2015), aromatic and highly unsaturated oxygen-poor compounds were preferentially removed from all samples during photo-irradiation (Figures 3E, 4). At the same time, however, a significant fraction of polyphenolic and polycyclic aromatics, as well as DBC, was preserved consistently in all samples, despite almost entire removal of CDOM (Figures 4, 5). This trend was confirmed by quantitative DBC analysis (Figure 5, Table S1). The photo-production of aromatic compounds, as suggested by Waggoner et al. (2015), is unlikely the reason for the presence of aromatics after our experiments, because most of them were already detected prior to the experiment and did not increase in relative intensity. Few newly formed compounds with aromatic character were detected (low H/C in Figure S6). Similar observations were also reported by Stubbins et al. (2010) and Rossel et al. (2013), who argued that these compounds did not lose their basic aromatic structure, but were molecularly modified so that they moved from another molecular category into "aromatics," possibly due to cleavage of aliphatic sidechains. A significant fraction of the polycyclic aromatics (and DBC) that remained after photo-incubation was bio-labile and removed in the following bio-incubation experiment (Figure 4E; Table S1). This enhanced bio-lability indicates major molecular transformations of the polycyclic aromatics during irradiation making them more accessible to microorganisms.

The reasons behind the observed photo-stability of some aromatics (as detected by FT-ICR-MS and as DBC) compared to almost complete loss of CDOM at $350 \mathrm{~nm}$ remains speculative at this point, but possibly some of the aromatic compounds in DOM absorb only UV-radiation at wavelengths $<350 \mathrm{~nm}$ and even below $300 \mathrm{~nm}$, which are almost absent in the spectrum of natural sunlight received at the Earth's surface (Figure S1). Furthermore, some aromatic moieties may also be protected from photodegradation because of their molecular environment they are embedded in (McNally et al., 2005). The photo-chemical stability of an aromatic component in DOM is of major relevance, because it determines the long-term stability of terrigenous components in the ocean. For instance, DBC accumulates over ten-thousands of years in the ocean (Dittmar and Paeng, 2009; Ziolkowski and Druffel, 2010), despite being highly susceptible to photodegradation (Stubbins et al., 2012). A minor photo-chemically resistant component in $\mathrm{DBC}$ would explain its long-term stability in the ocean.

Aside from the clear trend in aromaticity, photo-degradation caused a pronounced shift in molecular size. Larger molecules were preferentially removed over smaller molecules (Figures 3B, $\mathbf{4 H}$ ), while smaller molecules preferentially accumulated. This is not because aromatic compounds had a higher molecular mass than non-aromatic compounds, since both effects of photodegradation were clearly separated by the PCA (Figure 3). Cleavage of covalent bonds and the formation of low molecular weight compounds such as pyruvate, maleic or fumaric acid have been observed previously (Mopper et al., 1991; Gerdes et al., 1997). Many of these low-molecular mass compounds fall outside our analytical window defined largely by the solid 
A

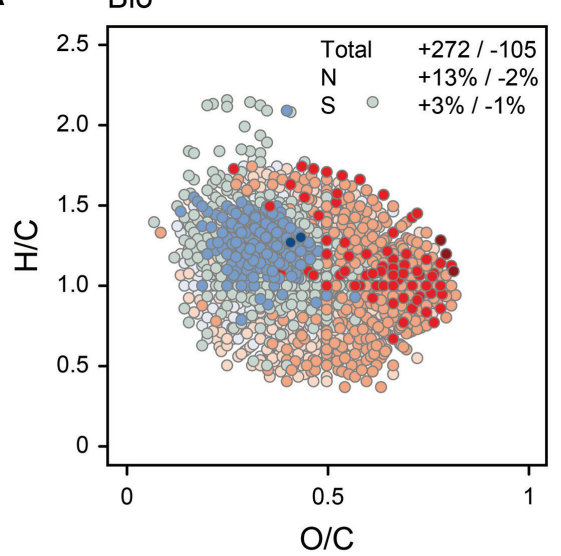

C

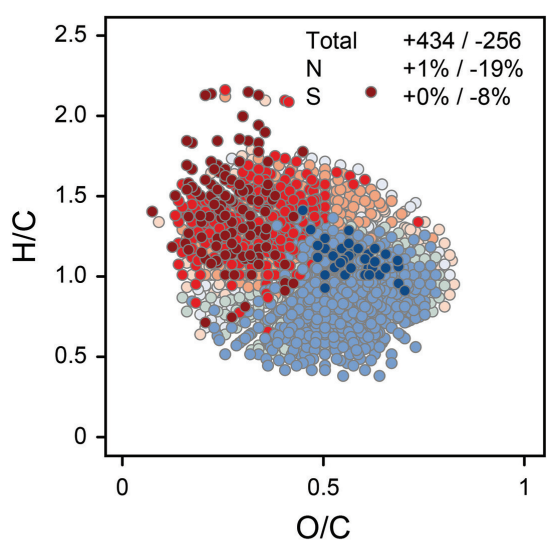

D
B
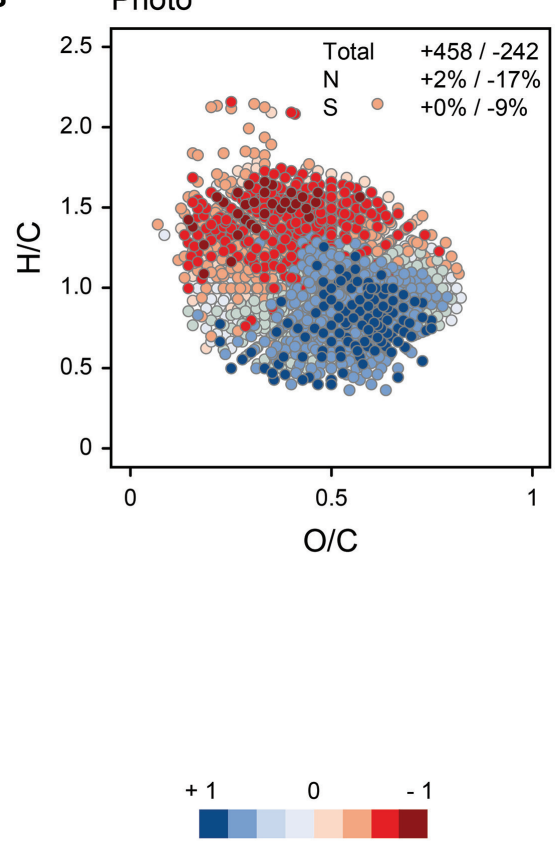

Pearson

Correlation Coefficient $r$

$(n=2167)$

E

DBC/DOC

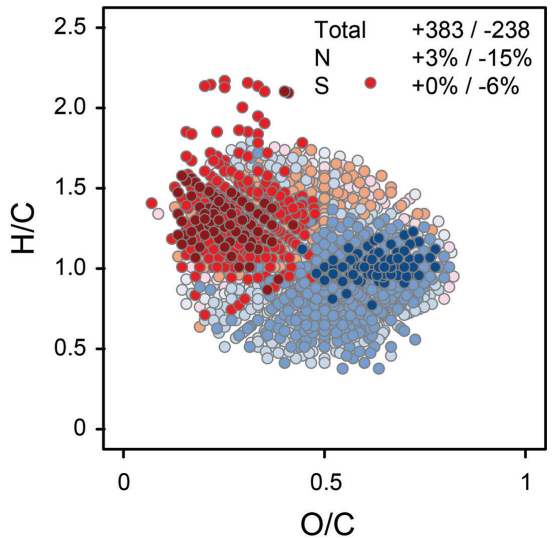

FIGURE 2 | Van Krevelen plots of the most intense molecular formulas from the 10 initial river samples (2167 formulas, see methods for details). Each dot represents one molecular formula. Color coded are correlation coefficients of the signal intensities of a given molecular formula vs. bio- and photo-reactivity of each sample ( $\triangle \mathrm{DOC}, \%$ of initial, Table 1), optical and molecular properties, respectively. The numbers in the individual panels are the numbers of molecular formulas that correlated positively $(+)$ and inversely $(-)$ with the respective parameter, on a $p<0.05(n=10, r>0.54)$ level, if not otherwise stated. The percentages show the proportion of nitrogen $(\mathrm{N})$ or sulfur $(\mathrm{S})$ containing molecular formulas that correlated positively $(+)$ and inversely $(-)$ with the respective parameter. Note, that for the reasons discussed in the main text, the correlation patterns of bio-degradation and DBC/DOC are very similar (but inverse), and there is a large similarity between photo-degradation and CDOM/DOC. (A) $\triangle \mathrm{DOC}$ (\% of initial) of the bio-degradation experiment ("D+") vs. FT-ICR-MS signal intensity. To illustrate general trends despite the overall weak correlation, numbers in this panel are for a $p<0.10$ significance level $(n=10, r>0.44)$. (B) $\Delta$ DOC (\% of initial) of the photo-degradation experiment ("L") vs. FT-ICR-MS signal intensity. (C) $\triangle$ DOC (\% of initial) of the bio-degradation experiment that followed photo-degradation ("L+") vs. FT-ICR-MS signal intensity. (D) CDOM/DOC ratio vs. FT-ICR-MS signal intensity. (E) DBC/DOC ratio vs. FT-ICR-MS signal intensity. 


\section{A}

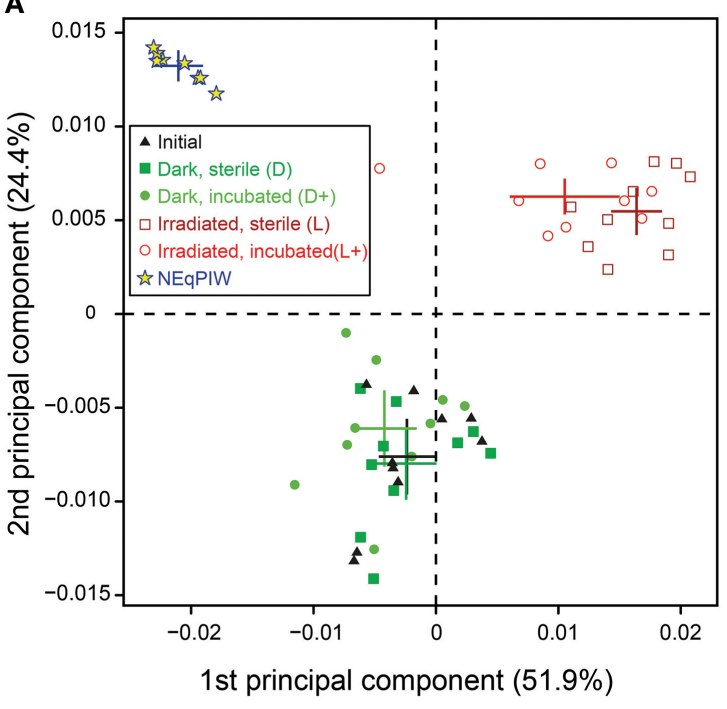

B

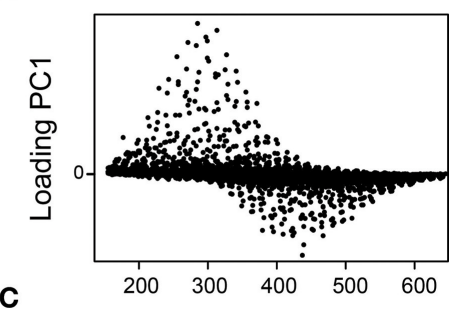

C

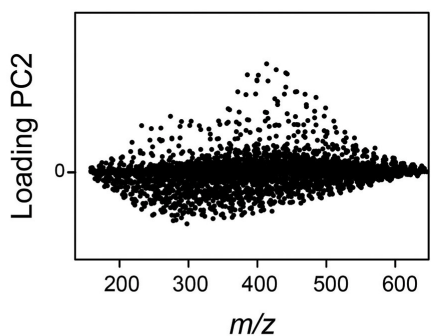

D

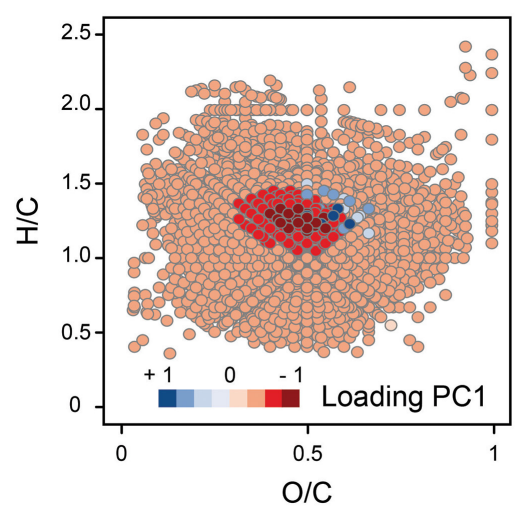

E

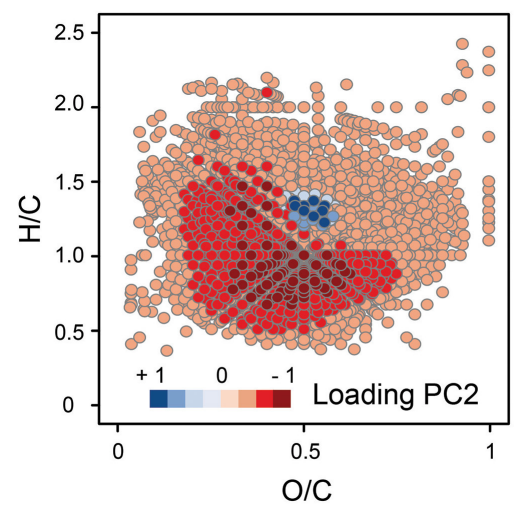

FIGURE 3 | Molecular compositional changes induced by bio- and photo-degradation. (A) Principle component analysis (PCA) score plot showing the first (52\% variance explained) and second component (24\% variance explained). Crosses represent average values ( $\pm 95 \%$ confidence interval) for the different experimental settings. Replicate analysis $(n=8)$ of DOM from North Equatorial Pacific Intermediate Water (NEqPIW) sample is included. (B) Loadings of PCA axis 1 plotted vs. mass to charge ratio (m/z) for each of the 4048 molecular formulas considered. (C) Loadings of PCA axis 2 plotted vs. mass to charge ratio (m/z) for each of the 4048 molecular formulas considered. (D) Loadings of PCA axis 1 plotted in van Krevelen space for each of the 4048 molecular formulas considered. (E) Loadings of PCA axis 2 plotted in van Krevelen space for each of the 4048 molecular formulas considered.

phase extraction (SPE) technique. While SPE via PPL adsorbers is one of the most efficient desalting techniques for natural $\mathrm{DOM}$, in terms of carbon recovery $(>50 \%)$ and complete removal of salt (Green et al., 2014), small ionic molecules and colloidal matter are not efficiently retained and are thus lost from the analytical window (Hawkes et al., 2016). Accordingly, the DOC extraction efficiency dropped from an average of $56 \%$ for initial and dark control samples to $35 \%$ after photo-irradiation. After subsequent bio-incubation, close to $50 \%$ of DOC was again recovered via solid phase extraction. This provides clear evidence for the production of bio-labile, low-molecular mass compounds during the photo-degradation experiment. This is consistent with the observed production of bio-labile DOM of low molecular weight during photodegradation experiments (Bano et al., 1998; Remington et al., 2011) and in the field (Lambert et al., 2016). The consumption of low-molecular mass compounds during bio-incubation was also evident on a molecular formula level. The shift in molecular size induced by photo-incubation was partially inverted during the subsequent bio-incubation (Figure 4H). Thus, low-molecular mass compounds were preferentially consumed over highmolecular mass compounds. This was observed in the incubation both with photo-irradiated and non-irradiated samples.

Different from a previous low-energy irradiation experiment with Amazon River water, where oxygen-rich aromatics where preferentially removed (Seidel et al., 2015), we observed the opposite trend (Figure 3E), i.e., low-oxygen compounds were preferentially destroyed, similar to Kujawinski et al. (2004). A major reaction pathway in the photo-oxidation of DOM is decarboxylation (Xie et al., 2004). In principle, this reaction should result in a lower $\mathrm{O} / \mathrm{C}$ ratio of the residual DOM, but at the same time new oxygen-containing functional groups can 


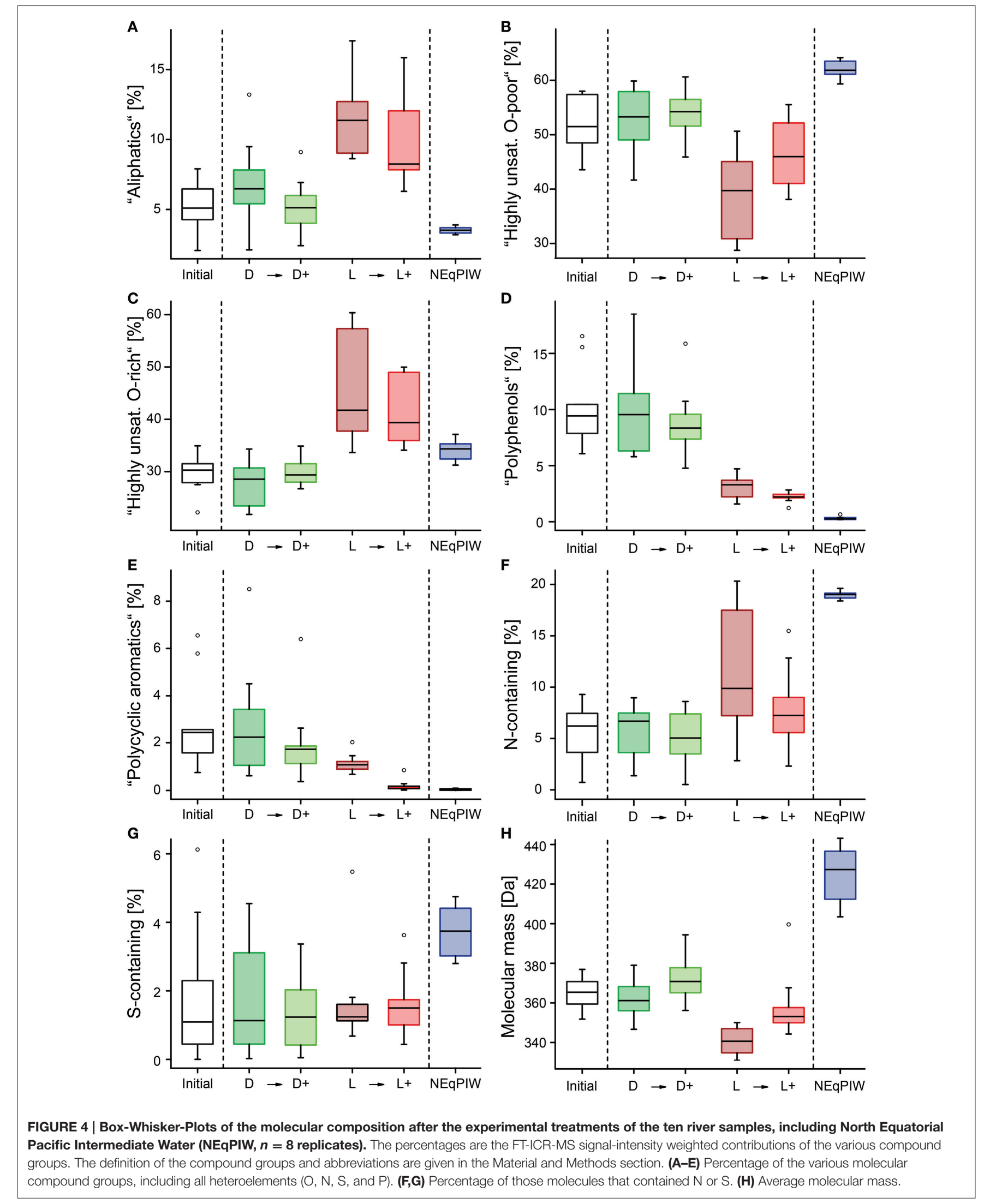


be produced during photo-oxidation (Xie et al., 2004). The labile compounds with low $\mathrm{O} / \mathrm{C}$ that disappeared during our irradiation experiment likely received an oxygen substituent and became more oxidized. Kendrick mass defect analysis (Stenson et al., 2003) supports this explanation that addition of oxygen atoms indeed occurred, and that at the same time oxygen was removed from some compounds via decarboxylation reactions. More details on the Kendrick mass defect analysis are provided in the supplementary information (Figure S3). Apparently, decarboxylation occurs quickly during the first stages of photo-degradation (Seidel et al., 2015), whereas the addition of additional oxygen is a subsequent reaction, causing a net shift toward higher O/C ratios in DOM on the longer term (this study). Consistent with our observations from FT-ICR-MS, lignin-derived phenols are oxidized when exposed to sunlight, and an increase of the acid to aldehyde ratio of lignin phenols likely results from the incorporation of oxygen during irradiation (Hernes and Benner, 2003).

After irradiation, the relative abundance of $\mathrm{N}$-containing compounds increased (Figure 4F). Photo-nitration is a possible explanation for this (Vione et al., 2014). For example, nitration of chlorophenols has been observed in the Rhone River delta as a result of the irradiation-induced formation of nitrogen dioxide radicals (Chiron et al., 2007). Photochemical reactions can also incorporate ammonium into dissolved organic forms (Kieber et al., 1997). Some of these photo-produced N-containing compounds were bio-labile and removed in the subsequent bioincubation (Figure 4F).

\section{Is There a Universal Molecular Signature of Resistant DOM across the Major World Rivers and the Deep Ocean?}

Multiple studies have made the observation that photoirradiation shifts the molecular signature of terrigenous DOM toward that of marine DOM (Dittmar et al., 2007; Stubbins et al., 2010; Rossel et al., 2013). The removal of characteristic terrigenous molecules by photo-degradation complicates the identification of terrestrial DOM in the ocean (Stubbins et al., 2010). Furthermore, it was suggested that the combined effects of photo- and microbial degradation may result in the accumulation of refractory molecules that share very similar molecular structures, independent of their original source (Jaffé et al., 2012). Convergence into a universal molecular composition in the course of degradation would imply that the long-term fate of DOM in the ocean is essentially source-independent.

At a first view, these previous observations were confirmed in our study. Overall trends in the molecular composition of DOM following irradiation with simulated sunlight were remarkably consistent between all ten rivers. Polyphenols (Figure 4D), condensed polycyclic aromatics (Figure 4E) and CDOM (Table 1) were preferentially removed over bulk DOC leaving behind DOM with a marine-like character, very similar to that of the old Pacific water mass (NEqPIW), included in our analysis. Also the frequency of molecular formulas on $\mathrm{O} / \mathrm{C}$ and $\mathrm{H} / \mathrm{C}$ scales in the photo-resistant component of DOM in the rivers was very similar to that of the marine sample

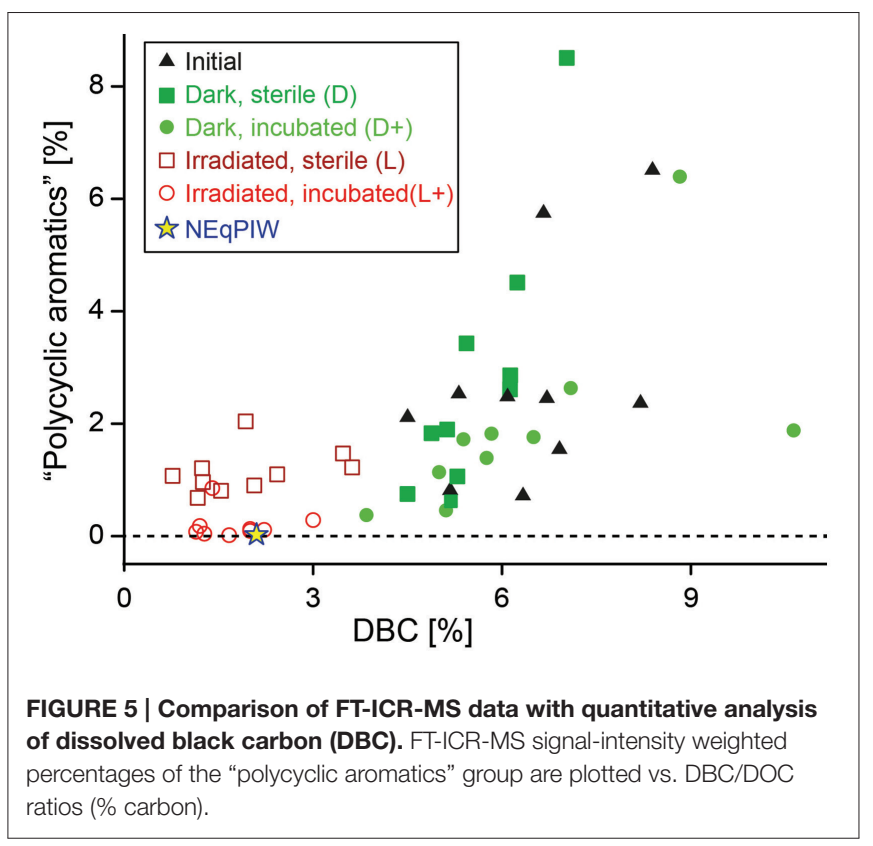

(Figure 6). An example of a single nominal mass (Figure S4) also suggests minimal differences between the photo-irradiated and marine DOM. Other molecular characteristics, however, showed a divergence of riverine and marine DOM due to the experimental treatment. Most notable, riverine compounds had on average much lower molecular masses than marine compounds (Figure 4H). Photo-degradation further increased this difference between riverine and marine (Figure 3), leaving a photo-resistant component behind that was more dissimilar to marine DOM in terms of molecular size. The rivers also contained much less nitrogen- and sulfur-containing compounds than the marine sample, and this difference only marginally changed due to the combined effect of photo- and biodegradation (Figures 4F,G).

For a more quantitative evaluation of the molecular dissimilarities across the different samples, we performed a BrayCurtis dissimilarity analysis. This approach takes into account the presence and absence of molecular formulas and their signal intensity distribution, i.e. the entire molecular fingerprint obtained by FT-ICR-MS. Replicate analysis of NEqPIW were dissimilar to about $5 \%$ on the Bray-Curtis scale. The initial river samples were dissimilar among each other to $17 \%$ (standard deviation $\pm 6 \%$ ), and dissimilar to the marine NEqPIW sample by $48 \%( \pm 5 \%)$. Surprisingly, the dissimilarity between samples remained unchanged at all stages of our experiments, and the bio- and photo-degraded samples ("L+") were 20\% ( $\pm 6 \%)$ dissimilar among each other and $46 \%( \pm 7 \%)$ dissimilar from marine NEqPIW. Even for the most recalcitrant compounds in our experiment, i.e. those compounds that were photo- and bioresistant (Table S2), the level of dissimilarity was still identical (19 $\pm 7 \%$ between rivers, and $42 \pm 7 \%$ between rivers and NEqPIW).

The same picture emerges from PCA analysis (Figure 3A). Photo-degradation moved the river samples away from NEqPIW on axis 1, and toward NEqPIW on the axis 2. The second 

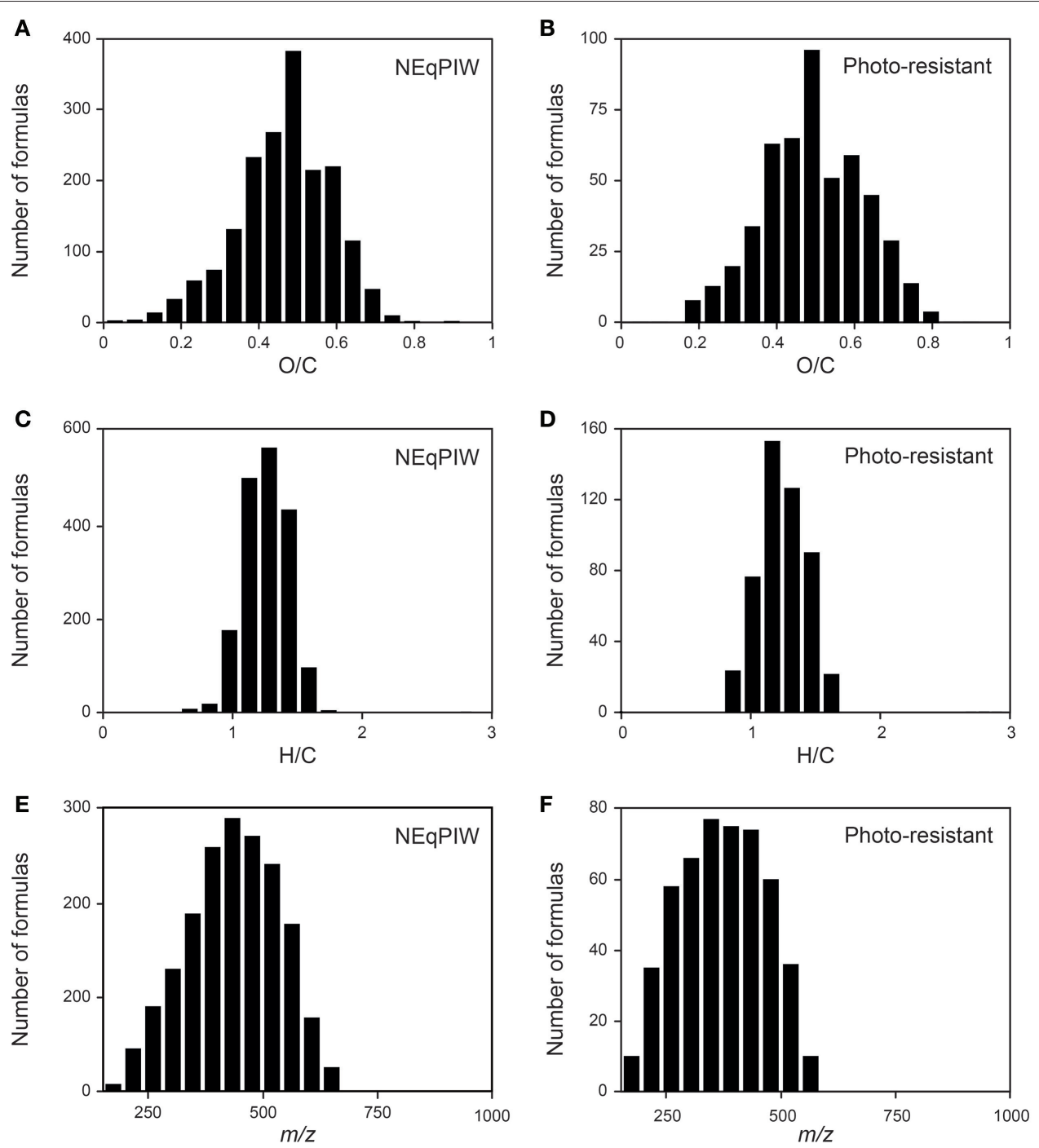

FIGURE 6 | Frequency abundance plot of the molecular formulas present in all of the photo-resistant fractions of the 10 rivers, compared to the molecular formulas detected in all of the 8 replicates of North Equatorial Pacific Intermediate Water (NEqPIW). The definition of "photo-resistant" is given in Table S2. (A,B) Frequency abundance distribution as a function of O/C ratio (C,D) Frequency abundance distribution as a function of H/C ratio (E,F) Frequency abundance distribution as a function of molecular mass.

axis represents largely the removal of aromatic compounds (Figure 3E), the first axis shifts in molecular mass (Figure 3B). To test whether the broad shift in molecular mass was the only reason for the differences between photo-irradiated and marine DOM, we repeated the PCA with a modified data set. This modification consisted of the removal of the broad molecular mass shift by normalizing each molecular formula to the sum of intensities of the respective nominal mass. In addition to this, only those molecular formulas were considered that cooccurred in all samples $(n=852)$. Even after this brute removal of variability between samples, the differences between riverine and marine DOM were preserved at all stages of experimental treatment (Figure S5). Thus, it is not only the molecular mass distribution, but all differences (as summarized in Figure 4, and others) that contribute to the molecular dissimilarity between samples.

Despite this overall high level of molecular dissimilarity, there was a very clear relationship between molecular dissimilarity and reactivity (Figure 7). The reactive component in DOM was molecularly very dissimilar between the rivers and to NEqPIW (Figures 7C,D). In other words, each river had a unique group of compounds that was labile or produced, despite the clear overall trend discussed in the previous section. The only exceptions were the Congo and Amazon Rivers whose photo-labile component shared a high level of similarity (Figure 7C), possibly because of their similarity in climate and vegetation. In all rivers, the reactive components shared no molecular similarity with marine DOM (Figures 7C,D), 


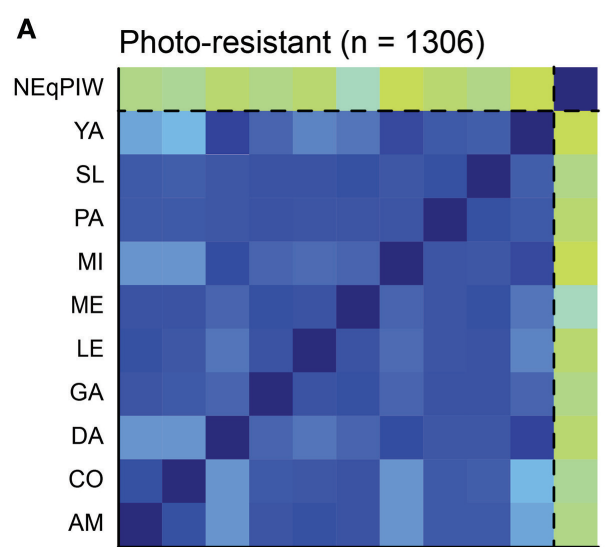

\section{C}

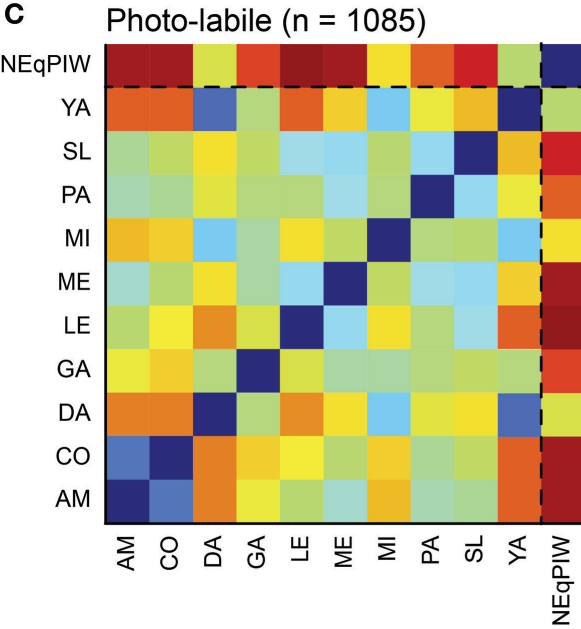

\section{B}

Photo-bio-resistant $(n=1226)$

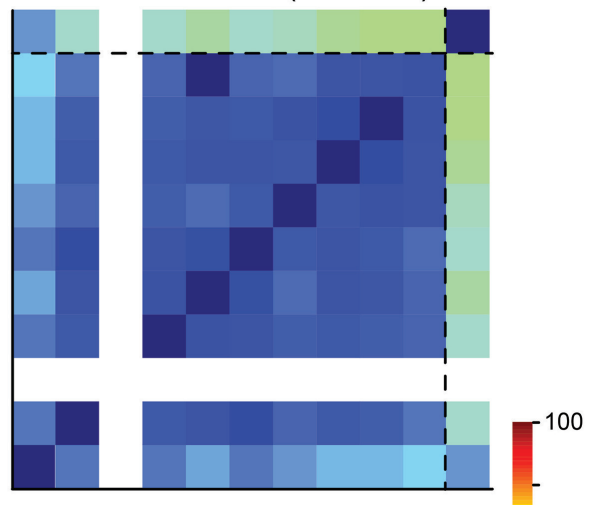

D Photo-produced $(n=1369)$

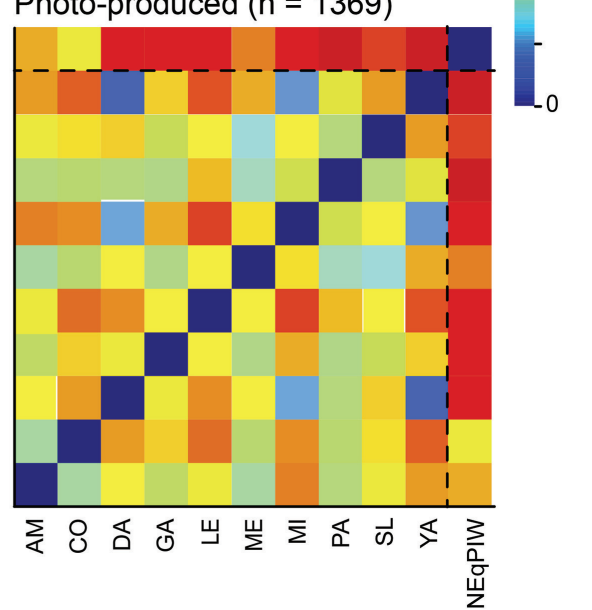

FIGURE 7 | Bray-Curtis dissimilarity matrices of the molecular formulas detected in the different reactivity fractions (for definition see Table S2) of the ten rivers, under consideration of FT-ICR-MS signal intensities. For comparison the marine sample was included, under consideration of the same molecular formulas as in each reactivity fraction. (A) Photo-resistant molecular formulas, signal intensities from experiment "L" were used. (B) Photo-bio-resistant molecular formulas, signal intensities from experiment "L+" were used. (C) Photo-labile molecular formulas, signal intensities from "initial" samples were used. (D) Photo-produced molecular formulas, signal intensities from experiment "L" were used. Abbreviations: AM, Amazon River; CO, Congo River; DA, Danube River; GA, Ganges Brahmaputra River; LE, Lena River; ME, Mekong River; MI, Mississippi River; PA, Paraná River; SL, St. Lawrence River; YA, Yangtze River; NEqPIW, North Equatorial Pacific Intermediate Water. Note that the "L+" experiment was not performed with Danube River water.

indicating that these compounds had efficiently been removed on their long journey into intermediate depths of the North Pacific. Compared to the reactive component of DOM, the rivers shared a relatively high molecular similarity in their resistant component (Figures 7A,B). This component potentially resists large-scale transport in the ocean. However, the large molecular dissimilarity even of this resistant riverine fraction with the marine sample indicates substantial molecular transformation prior to downward convection into the deep basins of the oceans. Autochthonous marine DOM seems to dominate the molecular composition of NEqPIW. It is possible that the different microbial communities in fresh and marine waters may cause molecular transformations in DOM that remained uncovered in this study. Long-term molecular transformations in the ocean may also result in almost complete loss of terrigenous DOM (Opsahl and Benner, 1997). But if the hypothesis is correct that the molecular composition of DOM converges in the course of degradation, irrespective of its original source, and that there is a universal molecular composition of recalcitrant DOM, different time scales and processes must be involved than considered in all experiments performed in this context to date.

\section{AUTHOR CONTRIBUTIONS}

AV designed sampling and performed photo- and biodegradation experiments. Molecular analyses were done by JN, TR, TD (FT-ICR-MS and black carbon), RS and PH (lignin). Statistical analyses were done by MZ, TR, and TD. The manuscript was written under the lead of TD and TR, with the contribution of all authors. 


\section{FUNDING}

RS was supported by the National Science Foundation through OCE-1333157/1464396. AV by the Academy of Finland (111761).

\section{ACKNOWLEDGMENTS}

We thank M. Friebe and I. Ulber for assistance in the lab and K. Klaproth for skilled technical support with the ESI-FT-ICRMS. We would like to thank those who contributed to sampling: H. and K. Aarnos (shipping organizations), E. M. Paolucci

\section{REFERENCES}

Aarnos, H., Ylostalo, P., and Vähätalo, A. V., (2012). Seasonal phototransformation of dissolved organic matter to ammonium, dissolved inorganic carbon, and labile substrates supporting bacterial biomass across the Baltic Sea. J. Geophys. Res. 117:G01004. doi: 10.1029/2010jg001633

Aufdenkampe, A. K., Mayorga, E., Raymond, P. A., Melack, J. M., Doney, S. C., Alin, S. R., et al. (2011). Riverine coupling of biogeochemical cycles between land, oceans, and atmosphere. Front. Ecol. Environ. 9:14. doi: 10.1890/ 100014

Bano, N., Moran, M., A., and Hodson, R. E. (1998). Photochemical formation of labile organic matter from two components of dissolved organic carbon in a freshwater wetland. Aquat. Microb. Ecol. 16, 95-102. doi: 10.3354/ame016095

Benner, R., and Kaiser, K. (2011). Biological and photochemical transformations of amino acids and lignin phenols in riverine dissolved organic matter. Biogeochemistry 102, 209-222. doi: 10.1007/s10533-010-9435-4

Chiron, S., Minero, C., and Vione, D. (2007). Occurrence of 2,4- dichlorophenol and of 2,4-dichloro-6-nitrophenol in the Rhone river delta (Southern France). Environ. Sci. Technol. 41, 3127-3133. doi: 10.1021/es0626638

Cole, J. J., Prairie, Y. T., Caraco, N. F. McDowell, W. H. Tranvik, L. J., Striegl, R. G. et al. (2007). Plumbing the global carbon cycle: Integrating inland waters into the terrestrial carbon budget. Ecosystems 10, 171-184. doi: 10.1007/s10021-0069013-8

Cory, R. M., Ward, C. P., Crump, B. C., and Kling, G. W. (2014). Sunlight controls water column processing of carbon in arctic fresh waters. Science 345, 925-928. doi: $10.1126 /$ science. 1253119

Dai, M., Yin, Z., Meng, F., Liu, Q., and Cai, W.-J. (2012). Spatial distribution of riverine DOC inputs to the ocean: an updated global synthesis. Curr. Opin. Env. Sust. 4, 170-178. doi: 10.1016/j.cosust.2012.03.003

Dittmar, T. (2008). The molecular level determination of black carbon in marine dissolved organic matter. Org. Geochem. 39, 396-407. doi: 10.1016/ j.orggeochem.2008.01.015

Dittmar, T., Koch, B. P., Hertkon, N., and Kattner, G. (2008). A simple and efficient method for solid phase extraction of dissolved organic matter (SPE-DOM) from seawater. Limnol. Oceanogr. Methods 6, 230-235. doi: 10.4319/lom.2008.6.230

Dittmar, T., and Paeng, J. (2009). A heat-induced molecular signature in marine dissolved organic matter. Nat. Geosci. 2, 175-179. doi: 10.1038/ngeo440

Dittmar, T., Whitehead, K., Minor, L., and Koch, B. P. (2007). Tracing terrigenous dissolved organic matter and its photochemical decay in the ocean by using liquid chromatography / mass spectrometry. Mar. Chem. 107, 378-387. doi: 10.1016/j.marchem.2007.04.006

Fichot, C. G., and Benner, R. (2012). The spectral slope coefficient of chromophoric dissolved organic matter (S275-295) as a tracer of terrigenous dissolved organic carbon in river-influenced ocean margins. Limnol. Oceanogr. 57, 1453-1466. doi: 10.4319/lo.2012.57.5.1453

Gerdes, R., Döhrle, W., Spiller, W., Schneider, G., Schnurpfeil, G., and SchulzEkloff, G. (1997). Photo-oxidation of phenol and monochlorophenols in oxygen-saturated aqueous solutions by different photosensitizers. J. Photochem. Photobiol. 111, 65-74. doi: 10.1016/S1010-6030(97)00209-8

Goldman, J. C., Caron, D. A., and Dennett, M. R. (1987). Regulation of gross growth efficiency and ammonium regeneration in bacteria by
(Paraná), D. O. E. Musibono (Congo), A. Shantz (Mekong), S. R. Khan (Ganges-Brahmaputra), Q. Huang (Yangtze), W. Schneider and B. Heim (Lena), Y. Gélinas (St. Lawrence), and A. Rivas and C. E. Rezende (Amazon), E. Petrescu (Danube), and H. E. Reader (Mississippi).

\section{SUPPLEMENTARY MATERIAL}

The Supplementary Material for this article can be found online at: http://journal.frontiersin.org/article/10.3389/feart. 2016.00085

substrate C:N ratio. Limnol. Oceanogr. 32, 1239-1252. doi: 10.4319/lo.1987.32. 6.1239

Gonsior, M., Peake, B. M., Cooper, W. T., D’Andrilli, J., and Cooper, W. J. (2008). Photochemically induced changed in dissolved organic matter identified by ultrahigh resolution fourier trans-form iron cyclontron resonance mass spectrometry. Environ. Sci. Technol. 43, 698-703. doi: 10.1021/es8022804

Graneli, W., Lindell, M., De Faria, B. M., and Esteves, F. D. A. (1998). Photoproduction of dissolved inorganic carbon in temperate and tropical lakes-dependence on wavelength band and dissolved organic carbon concentration. Biogeochem. 43, 175-195. doi: 10.1023/A:1006042629565

Green, N. W., Perdue, E. M., Aiken, G. R., Butler, K. D., Chen, H., Dittmar, T. et al. (2014). An intercomparison of three methods for the large-scale isolation of oceanic dissolved organic matter. Mar. Chem. 161, 14-19. doi: 10.1016/j.marchem.2014.01.012

Hawkes, J. A., Hansen, C. T., Goldhammer, T., Bach, W., and Dittmar, T. (2016). Molecular alteration of marine dissolved organic matter under experimental hydrothermal conditions. Geochim. Cosmochim. Acta 175, 68-85. doi: 10.1016/j.gca.2015.11.025

Hedges, J. I., and Ertel, J. R. (1982). Characterization of lignin by gas capillary chromatography of cupric oxide oxidation-products. Anal. Chem. 54, 174-178. doi: 10.1021/ac00239a007

Hedges, J. I., Keil, R. G., and Benner, R. (1997). What happens to terrestrial organic matter in the ocean? Org. Geochem. 27, 195-212. doi: 10.1016/S0146-6380(97) 00066-1

Hernes, P. J., and Benner, R. (2003). Photochemical and microbial degradation of dissolved lignin phenols: Implications for the fate of terrigenous dissolved organic matter in marine environments. J. Geophys. Res. 108, 3291. doi: 10.1029/2002JC001421

Hertkorn, N., Benner, R., Frommberger, M., Schmitt-Kopplin, P., Witt, M., Kaiser, K., et al. (2006). Characterization of a major refractory component of marine dissolved organic matter. Geochim. Cosmochim. Acta 70, 2990-3010. doi: 10.1016/j.gca.2006.03.021

Jaffé, R., Ding, Y., Niggemann, J., Vähätalo, A. V., Stubbins, A., Spencer, R. G. M., et al. (2013). Global charcoal mobilization from soils via dissolution and riverine transport to the oceans. Science 340, 345-347. doi: 10.1126/science.1231476

Jaffé, R., Yamashita, Y., Maie, N., Cooper, W. T., Dittmar, T., Dodds, W. K., et al. (2012). Dissolved organic matter in headwater streams: compositional variability across climatic regions of North America. Geochim. Cosmochim. Acta 94, 95-108. doi: 10.1016/j.gca.2012.06.031

Karentz, D., Bothwell, M. L., Coffin, R. B., Hanson, A., Herndl, G. J., Kilham, S. S., et al. (1994). Impact of UV-B radiation on pelagic freshwater ecosystems: Report of working group on bacteria and phytoplankton. Arch. Hydrobiol. 43, 31-69.

Kieber, R. J., Hydro, L. H., and Seaton, P. J., (1997). Photooxidation of triglycerides and fatty acids in seawater: implication toward the formation of marine humic substances. Limnol. Oceanogr. 42, 1454-1462. doi: 10.4319/lo.1997.42. 6.1454

Kim, S., Kaplan, L. A., and Hatcher, P. G., (2006). Biodegradable dissolved organic matter in a temperate and a tropical stream determined from ultrahigh resolution mass spectrometry. Limnol. Oceanogr. 51, 1054-1063. doi: 10.4319/lo.2006.51.2.1054 
Koch, B. P., and Dittmar, T., (2006). From mass to structure: an aromaticity index for high-resolution mass data of natural organic matter. Rapid Comm. Mass Spectrom. 20, 926-993. doi: 10.1002/rcm.2386

Koch, B. P., and Dittmar, T., (2016). Erratum: From mass to structure: an aromaticity index for high-resolution mass data of natural organic matter. Rapid Comm. Mass Spectrom. 30, 250. doi: 10.1002/rcm.7433

Koch, B. P., Dittmar, T., Witt, M., and Kattner, G., (2007). Fundamentals of molecular formula assignment to ultrahigh resolution mass data of natural organic matter. Anal. Chem. 79, 1758-1763. doi: 10.1021/ac061949s

Koehler, B., Landelius, T., Weyhenmeyer, G. A., Machida, N., and Tranvik, L. J. (2014). Sunlight-induced carbon dioxide emissions from inland waters. Glob. Biogeochem. 28, 696-711. doi: 10.1002/2014GB004850

Kujawinski, E. B., Del Vecchio, R., Blough, N. V., Klein, G. C., and Marshall, A. G. (2004). Probing molecular-level transformations of dissolved organic matter: insights on photochemical degradation and protozoan modification of DOM from electrospray ionization Fourier transform ion cyclotron resonance mass spectrometry. Mar. Chem. 92, 23-37. doi: 10.1016/j.marchem.2004.06.038

Lalonde, K., Vähätalo, A. V., and Gelinas, Y. (2014). Revisiting the disappearance of terrestrial dissolved organic matter in the ocean: a d13C study. Biogeosciences 11, 3707-3719. doi: 10.5194/bg-11-3707-2014

Lambert, T., Darchambeau, F., Bouillon, S., Alhou, B., Jean-Daniel, M., Cristian, R., et al. (2015). Landscape control on the spatial and temporal variability of chromophoric dissolved organic matter and dissolved organic carbon in large African rivers. Ecosystems 18, 1224-1239. doi: 10.1007/s10021-015-9894-5

Lambert, T., Bouillon, S., Darchambeau, F., Massicotte, P., and Borges, A. V. (2016). Shift in the chemical composition of dissolved organic matter in the Congo River network. Biogeosci. Discuss. 1-49. doi: 10.5194/bg-2016-240

Lapierre, J.-F., Guillemette, F., Berggren, M., and del Giorgio, P. A. (2013). Increases in terrestrially derived carbon stimulate organic carbon processing and CO2 emissions in boreal ecosystems. Nat. Comm. 4, 2972. doi: $10.1038 /$ ncomms 3972

Lindell, M. J., Graneli, W., and Tranvik, L. J. (1995). Enhanced bacterial growth in response to photochemical transformation of dissolved humic matter. Limnol. Oceanogr. 40, 195-199. doi: 10.4319/lo.1995.40.1.0195

Lund, V., and Hongve, D. (1994). Ultraviolet irradiated water containing humic substances inhibits bacterial metabolism. Water Res. 28, 1111-1116. doi: 10.1016/0043-1354(94)90197-X

Mattsson, T., Kortelainen, P., Laubel, A., Evans, D., Pujo-Pay, M., Räike, A., et al. (2009). Export of dissolved organic matter in relation to land use along a European climatic gradient. Sci. Total Environ. 407, 1967-1976. doi: 10.1016/j.scitotenv.2008.11.014

McNally, A. M., Moody, E. C., and Mcneill, K. (2005). Kinetics and mechanism of the sensitized photodegradation of lignin model compounds. Photochem. Photobiol. Sci. 4, 268-274. doi: 10.1039/b416956e

Medeiros, P. M., Seidel, M., Ward, N. D., Carpenter, E. J., Gomes, H. R., Niggemann, J., et al. (2015). Fate of the Amazon River dissolved organic matter in the tropical Atlantic Ocean. Glob. Biogeochem. Cycles 29, 677-690. doi: 10.1002/2015GB005115

Miller, W. L., and Moran, M. A. (1997). Interaction of photochemical and microbial processes in the degradation of refractory dissolved organic matter from a coastal marine environment. Limnol. Oceanogr. 42, 1317-1324. doi: 10.4319/lo.1997.42.6.1317

Miller, W. L., and Zepp, R. G. (1995). Photochemical production of dissolved inorganic carbon from terrestrial organic matter: Significance to the oceanic organic carbon cycle. Geophys. Res. Lett. 22, 417-420. doi: 10.1029/94GL03344

Mopper, K., Zhou, X., Kieber, D. J., Sikorski, R. J., and Jones, R. N. (1991). Photochemical degradation of dissolved organic carbon and its impact on oceanic carbon cycle. Nature 353, 60-62. doi: 10.1038/353060a0

Obernosterer, I., and Benner, R. (2004). Competition between biological and photochemical processes in the mineralization of dissolved organic carbon. Limnol. Oceanogr. 49, 117-124. doi: 10.4319/lo.2004.49.1.0117

Obernosterer, I., Reitner, B., and Herndl, G. J. (1999). Contrasting effects of solar radiation on dissolved organic matter and its bioavailability to marine bacterioplankton. Limnol. Oceanogr. 44, 1645-1654. doi: 10.4319/lo.1999.44.7.1645

Oksanen, J., Blanchet, F. G., Kindt, R., Legendre, P., Minchin, P. R., O’Hara, R. B., et al. (2013). Vegan: Community Ecology Package. R package version 2.0-10. Available online at: http://CRAN.R-project.org/package=vegan
Opsahl, S., and Benner, R. (1997). Distribution and cycling of terrigenous dissolved organic matter in the ocean. Nature 386, 480-482. doi: 10.1038/386480a0

Opsahl, S., and Benner, R. (1998). Photochemical reactivity of dissolved lignin in river and ocean waters. Limnol. Oceanogr. 43, 1297-1304. doi: 10.4319/lo.1998.43.6.1297

Osburn, C. L., Retamal, L., and Vincent, W. F. (2009). Photoreactivity of chromophoric dissolved organic matter transported by the Mackenzie River to the Beaufort Sea, Mar. Chem. 115, 10-20. doi: 10.1016/j.marchem.2009.05.003

Osterholz, H., Niggemann, J., Giebel, H. A., Simon, M., and Dittmar, T. (2015). Inefficient microbial production of refractory dissolved organic matter in the ocean. Nat. Comm. 6:7422. doi: 10.1038/ncomms8422

Petersen, J. E., and Kemp, W. M. (2010). "Mesocosms: enclosed experimental ecosystems in ocean science," in Encyclopedia of Ocean Sciences, 2nd Edn., eds J. H. Steele, K. K. Turekian, and S. A. Thorpe (Amsterdam: Elsevier), 732-747.

Raymond, P. A., Hartmann, J., Lauerwald, R., Sobek, S., McDonald, C., Hoover, M., et al. (2013). Global carbon dioxide emissions from inland waters. Nature 503, 355-359. doi: 10.1038/nature12760

Raymond, P. A., and Spencer, R. G. M. (2015). "Riverine dissolved organic matter," in Biogeochemistry of Marine Dissolved Organic Matter. 2nd Edn., eds D. A. Hansell and C. A. Carlson (Amsterdam: Elsevier), 509-533.

Remington, S., Krusche, A., and Richey, J. (2011). Effects of DOM photochemistry on bacterial metabolism and $\mathrm{CO}_{2}$ evasion during falling water in a humic and a whitewater river in the Brazilian Amazon. Biogeochemistry 105, 185-200. doi: 10.1007/s10533-010-9565-8

Riedel, T., Iden, S., Geilich, J., Wiedner, K., Durner, W., and Biester, H. (2014). Changes in the molecular composition of organic matter leached from an agricultural topsoil following addition of biomass-derived black carbon (biochar). Org. Geochem. 69, 52-60. doi: 10.1016/j.orggeochem.2014.02.003

Riedel, T., and Dittmar, T. (2014). A method detection limit for the analysis of natural organic matter via fourier transform ion cyclotron resonance mass spectrometry. Anal. Chem. 86, 8376-8382. doi: 10.1021/ac501946m

Rossel, P. E., Vähätalo, A. V., Witt, M., and Dittmar, T. (2013). Molecular composition of dissolved organic matter from a wetland plant (Juncus effusus) after photochemical and microbial decomposition (1.25 yr): Common features with deep sea dissolved organic matter. Org. Geochem. 60, 62-71. doi: 10.1016/j.orggeochem.2013.04.013

Santín, C., Doerr, S. H., Kane, E. S., Masiello, C. A., Ohlson, M., Dittmar, J. M., et al. (2016). Towards a global assessment of pyrogenic carbon from vegetation fires. Glob. Change Biol. 22, 76-91. doi: 10.1111/gcb.12985

Seidel, M., Beck, M., Riedel, T., Waska, H., Suryaputra, I. G. N. A., Schnetger, B., et al. (2014). Biogeochemistry of dissolved organic matter in an anoxic intertidal creek bank. Geochim. Cosmochim. Acta 140, 418-434. doi: 10.1016/j.gca.2014.05.038

Seidel, M., Yager, P. L., Ward, N. D., Carpenter, E. J., Gomes, H. R., Krusche, A. V., et al. (2015). Molecular-level changes of dissolved organic matter along the Amazon River-to-ocean continuum. Mar. Chem. 177, 218-231. doi: 10.1016/j.marchem.2015.06.019

Spencer, R. G. M., Aiken, G. R., Dyda, R. Y., Butler, K. D., Bergamaschi, B. A., and Hernes, P. J. (2010). Comparison of XAD with other dissolved lignin isolation techniques and a compilation of analytical improvements for the analysis of lignin in aquatic settings. Org. Geochem. 41, 445-453. doi: 10.1016/j.orggeochem.2010.02.004

Spencer, R. G. M., Stubbins, A., Hernes, P. J., Andy, B., Kenneth, M., Anthony, K. A., et al. (2009). Photochemical degradation of dissolved organic matter and dissolved lignin phenols from the Congo River. J. Geophys. Res. 114:G03010. doi: 10.1029/2009JG000968

Stenson, A. C., Marshall, A. G., and Cooper, W. T. (2003). Exact masses and chemical formulas of individual Suwannee River fulvic acids from ultrahigh resolution electrospray ionization Fourier transform ion cyclotron resonance mass spectra. Anal. Chem. 75, 1275-1284. doi: 10.1021/ac026106p

Stubbins, A., Niggemann, J., and Dittmar, T. (2012). Photo-lability of deep ocean dissolved black carbon. Biogeoscience 9, 1661-1670. doi: 10.5194/bg-9-16612012

Stubbins, A., Spencer, R. G. M., Chen, H., Hatcher, P. G., Mopper, K., Hernes, P. J., et al. (2010). Illuminated darkness: molecular signatures of Congo River dissolved organic matter and its photochemical alteration as revealed by ultrahigh precision mass spectrometry. Limnol. Oceanogr 55, 1467-1477. doi: 10.4319/lo.2010.55.4.1467 
Stubbins, A., Spencer, R. G. M., Mann, P. J., Holmes, R. M., McClelland, J. W., Niggemann, J., et al. (2015). Utilizing colored dissolved organic matter to derive dissolved black carbon export by Arctic Rivers. Front. Earth Sci. 3:63. doi: 10.3389/feart.2015.00063

Stuiver, M., Quay, P. D., and Ostlund, H. G. (1983). Abyssal Water Carbon14 Distribution and the age of the world oceans. Science 219, 849-851. doi: $10.1126 /$ science. 219.4586 .849

Šantl-Temkiv, T., Finster, K., Dittmar, T., Hansen, B. M., Thyrhaug, R., Woetmann Nielsen, N., et al. (2013). Hailstones: a window into the microbial and chemical inventory of a storm cloud. PLOS ONE 8:e53550. doi: 10.1371/journal.pone. 0053550

Tranvik, L. J., and Bertilsson, S. (2001). Contrasting effects of solar UV radiation on dissolved organic sources for bacterial growth. Ecol. Lett. 4, 458-463. doi: 10.1046/j.1461-0248.2001.00245.x

Vähätalo, A. V., and Wetzel, R. G. (2008). Long-term photochemical and microbial decomposition of wetland-derived dissolved organic matter with alteration of 13C:12C mass ratio. Limnol. Oceanogr. 53, 1387-1392. doi: 10.4319/lo.2008. 53.4.1387

Vähätalo, A. V., Salonen, K., Münster, U., Järvinen, M., and Wetzel, R. G. (2003). Photochemical transformation of allochtonous organic matter provides bioavailable nutrients in a humic lake. Arch. Hydrobiol. 156, 287-314. doi: 10.1127/0003-9136/2003/0156-0287

Vione, D., Minella, M., Maurino, V., and Minero, C. (2014). Indirect photochemistry in sunlit surface waters: photoinduced production of reactive transient species. Chem. A Eur. J. 20, 10590-10606. doi: 10.1002/chem.201 400413

Waggoner, D. C., Chen, H., Willoughby, A. S., and Hatcher, P. G. (2015). Formation of black carbon-like and alicyclic aliphatic compounds by hydroxyl radical initiated degradation of lignin. Org. Geochem. 82, 69-76. doi: 10.1016/ j.orggeochem.2015.02.007
Wagner, S., Riedel, T., Niggemann, J., Vähätalo, A. V., Dittmar, T., and Jaffé, R. (2015). Linking the molecular signature of heteroatomic dissolved organic matter to watershed characteristics in world rivers. Env, Sci. Technol. 49, 13798-13806. doi: 10.1021/acs.est.5b00525

Ward, N. D., Keil, R. G., Medeiros, P. M., Brito, D. C., Cunha, A. C., Richey, T., et al. (2013). Degradation of terrestrially derived macromolecules in the Amazon River. Nat. Geosci. 6, 530-533. doi: 10.1038/nge o1817

Wilson, H. F., and Xenopoulos, M. A. (2009). Effects of agricultural land use on the composition of fluvial dissolved organic matter. Nat. Geosci. 2, 37-41. doi: 10.1038/ngeo391

Xie, H., Zafiriou, O. C., Cai, W.-J., Zepp, R. G., and Wang, Y. (2004). Photooxidation and its effects on the carboxyl content of dissolved organic matter in two coastal rivers in the southeastern United States. Environ. Sci. Technol. 38, 4113-4119. doi: 10.1021/es035407t

Ziolkowski, L. A., and Druffel, E. R. M. (2010). Aged black carbon identified in marine dissolved organic carbon. Geophys. Res. Lett. 37:L16601. doi: 10.1029/ 2010GL043963

Conflict of Interest Statement: The authors declare that the research was conducted in the absence of any commercial or financial relationships that could be construed as a potential conflict of interest.

Copyright (๑) 2016 Riedel, Zark, Vähätalo, Niggemann, Spencer, Hernes and Dittmar. This is an open-access article distributed under the terms of the Creative Commons Attribution License (CC BY). The use, distribution or reproduction in other forums is permitted, provided the original author(s) or licensor are credited and that the original publication in this journal is cited, in accordance with accepted academic practice. No use, distribution or reproduction is permitted which does not comply with these terms. 